\title{
CURTA-METRAGEM E SUSTENTABILIDADE: MULTILETRAMENTOS NO SUBPROJETO LETRAS- PORTUGUÊS DO PIBID
}

\author{
Maristela Pereira Fritzen \\ Universidade Regional de Blumenau \\ Aline Fernanda Guse \\ Universidade Regional de Blumenau \\ Eriberto Manoel Moreira \\ Universidade Regional de Blumenau \\ Andressa Regiane Gesser \\ Universidade Regional de Blumenau \\ Larissa Patricia Theiss \\ Universidade Regional de Blumenau
}

\section{Resumo}

Propomos neste trabalho fazer um relato de experiência do Subprojeto LetrasPortuguês do PIBID - Programa Institucional de Bolsas de Iniciação à Docência, posta em prática em uma escola pública de Blumenau, SC. Uma das ações do Subprojeto foi o desenvolvimento de um projeto de letramento interdisciplinar, com turmas do ensino fundamental II, que buscasse responder a questões relacionadas à temática da sustentabilidade socioambiental. Dentre os objetivos do projeto estavam: promover reflexões sobre a sustentabilidade no âmbito social, ambiental e econômico; possibilitar ações pedagógicas interdisciplinares na escola; e inserir os alunos em práticas de multiletramentos na produção de filmes de curtametragem, como produto final. A metodologia de trabalho incluiu etapas de planejamento das ações e avaliação em conjunto com o Subprojeto de Ciências do PIBID, em andamento na mesma escola. Foram elaboradas sequências didáticas para o estudo e produção de gêneros discursivos envolvidos no projeto, com destaque para o conto e o roteiro. Na finalização dos trabalhos, foi possível constatar a importância do desenvolvimento de projetos na escola, possibilitando aos alunos a construção de conhecimentos significativos e envolvimento em ações que vão além do aprendizado dos conteúdos curriculares.

Palavras-chave: Projeto de Letramento; Interdisciplinaridade;

Sustentabilidade. 


\title{
SHORT FILM AND SUSTAINABILITY: MULTIPLE LITERACIES IN PIBID'S PORTUGUESE LANGUAGE SUBPROJECT
}

\begin{abstract}
This work intends to report the experiences in PIBID's (Programa Institucional de Bolsas de Iniciação à Docência, Teaching Training Program) Portuguese Language Subproject, implemented in a public school in Blumenau, SC. One of the actions performed in this Subproject was the development of an interdisciplinary literacy project, in Elementary School groups, which searches for answers to issues related to social and environmental sustainability. Among the objectives of this project, we can list: fomenting reflections about sustainability in social, environmental and economic scopes; enabling interdisciplinary pedagogical actions in the school; and inserting students in multiple literacy practices to create short films as a final product. The methodology includes steps of action planning and evaluation along with the PIBID's Science Subproject, in progress at the same school. Didactic sequences were developed to study and produce the textual genres involved in the project with emphasis on "short story" and "script". At the completion of this work, it was possible to establish the importance given to the development of different projects in this particular school, enabling students to gather significant knowledge and engage in actions that go further than learning the syllabus content.
\end{abstract}

Keywords: Literacy Project; Interdisciplinarity; Sustainability. 


\section{Considerações iniciais}

Em 2013, desenvolvemos um projeto de letramentos interdisciplinar, por meio do Subprojeto Letras-Português do PIBID, em uma escola da rede pública municipal de ensino da cidade de Blumenau, SC. Esse projeto, intitulado "Curta-metragem na sala de aula", tinha como meta atender aos objetivos centrais do referido Subprojeto, dos quais destacamos "desenvolver estratégias didáticas a fim de que os alunos da educação básica ampliem sua competência comunicativa, especialmente no uso da escrita de narrativas" (FRITZEN, 2011). Tendo em vista esse objetivo, e após ações anteriores de diagnóstico da escrita dos alunos, passamos a desenvolver o projeto de letramento com três turmas da $8^{\mathrm{a}}$ série ${ }^{1}$.

O projeto teve como perspectiva possibilitar o desenvolvimento de práticas de linguagem que exigem os multiletramentos. $\mathrm{O}$ conceito aponta tanto para a multiplicidade cultural na contemporaneidade, quanto para a "multiplicidade semiótica de constituição dos textos" (ROJO; MOURA, 2012, p. 12). O trabalho se desenrolou com o estudo dos vários gêneros discursivos (BAKHTIN, 1997) que envolvem a criação e a produção de um filme de curta-metragem. A fim de ampliar a abrangência do projeto e promover ações interdisciplinares na escola, foi feita uma parceria com o Subprojeto de Ciências do PIBID, que mantém na escola o Clube de Ciências. O tema escolhido foi a sustentabilidade socioambiental. Além do PIBID de Ciências, professores de outras áreas também contribuíram de forma direta ou indireta, viabilizando o projeto, envolvendo, assim, boa parte da comunidade escolar.

A propósito da temática, por ser um assunto amplamente discutido na atualidade, há a necessidade contínua de desenvolver nas

\footnotetext{
$\left.{ }^{1}\right\urcorner \mathrm{Na}$ época do projeto, essas turmas ainda eram designadas pela nomenclatura antiga, correspondente ao atual $9^{\circ}$ ano.

Olh@res, Guarulhos, v. 2, n. 2, p. 352-374. Dezembro, 2014.
} 
crianças e jovens em fase escolar a consciência ecológica. Os próprios documentos oficiais, como os PCN (1998), por meio dos temas transversais, abordam essa questão.

A principal função do trabalho com o tema Meio Ambiente é contribuir para a formação de cidadãos conscientes, aptos a decidir e atuar na realidade socioambiental de um modo comprometido com a vida, com o bem-estar de cada um e da sociedade, local e global. Para isso é necessário que, mais do que informações e conceitos, a escola se proponha a trabalhar com atitudes, com formação de valores, com o ensino e aprendizagem de procedimentos. E esse é um grande desafio para a educação. Gestos de solidariedade, hábitos de higiene pessoal e dos diversos ambientes, participação em pequenas negociações são exemplos de aprendizagem que podem ocorrer na escola. (BRASIL, 1998, p. 187).

Esse projeto tomou por base as propostas teóricas dos estudos dos letramentos e dos multiletramentos (KLEIMAN, 1995; 2008; ROJO; MOURA, 2012), bem como sua abordagem para o ensino, na forma de projetos de letramentos (KLEIMAN, 2000; OLIVEIRA; TINOCO; SANTOS, 2011; KLEIMAN; CENICEROS; TINOCO, 2013). Também serviu de subsídio teórico a abordagem dos gêneros discursivos (BAKHTIN, 1997) necessários para a criação de um curtametragem.

Neste relato de experiência, expomos inicialmente as ações do Subprojeto Letras-Português do PIBID; em seguida contextualizamos brevemente a escola, campo no qual o projeto foi desenvolvido; depois abordamos a importância do trabalho com projetos nas escolas fazendo a ponte com a nossa experiência junto às turmas das $8^{a}$ séries; finalmente, tecemos nossas conclusões a respeito dessa ação do PIBID Letras.

\section{O Subprojeto Letras-Português do PIBID e as primeiras ações}

O Subprojeto Letras-Português do PIBID da FURB (Universidade Regional de Blumenau) iniciou suas ações em agosto de 2012, em uma escola municipal na cidade de Blumenau, Santa

Olh@res, Guarulhos, v. 2, n. 2, p. 352-374. Dezembro, 2014. 
Catarina, contando com a participação de cinco bolsistas, acadêmicos do curso de Letras da Universidade, de uma professora supervisora, representante da escola, e das professoras coordenadoras do Subprojeto que colaboraram na formação teórica dos bolsistas de iniciação à docência, além de coordenarem as demais ações do Subprojeto.

Dentre os objetivos centrais do Subprojeto, estavam: (i) levantar um diagnóstico detalhado da escrita de alunos do Ensino Fundamental II, (ii) analisar essa produção a partir de fundamentação teórica consistente para, em conjunto com o professor supervisor, (iii) desenvolver estratégias didáticas a fim de que os alunos da educação básica ampliem sua competência comunicativa, especialmente no uso da escrita de narrativas.

Inicialmente, para conhecermos melhor os alunos com os quais iríamos trabalhar, aplicamos um questionário com questões abertas e fechadas. As questões relacionavam-se a dados pessoais, à instrução dos pais ou responsáveis, aos hábitos de leitura dos alunos e dos pais (inclusive, se os pais costumavam ler histórias para eles quando pequenos) e também sobre as condições dos alunos quanto ao uso de ferramentas de tecnologia, entre outros. Essas informações seriam importantes, pois nos auxiliariam no diagnóstico que seria feito na sequência dos trabalhos, principalmente, o relacionado à formação do esquema narrativo das crianças.

Atendendo aos objetivos do Subprojeto, necessitávamos, então, conhecer o nível de desenvolvimento do esquema narrativo ou gramática das estórias (CABRAL, 1991; SILVA; SPINILLO, 1998; 2000; GUIMARÃES, 2006; ABREU, 2012) desses alunos. Para tanto, aplicamos a todas as turmas do Ensino Fundamental II, uma proposta de produção textual a partir de seis imagens, que, devidamente sequenciadas, formavam uma história. Após a coleta das narrativas, digitamos essas produções para um diagnóstico inicial. Para que pudéssemos fazer uma melhor análise dessas produções, tivemos Olh@res, Guarulhos, v. 2, n. 2, p. 352-374. Dezembro, 2014. 
algumas formações sobre narrativas e seus elementos, além da leitura e reflexão de artigos e livros sobre projetos feitos com aplicações, análises e comparações de histórias.

A análise das produções dos alunos teve como referencial teórico de base as regras do modelo de Stein \& Glenn (1979 apud SCLIAR-CABRAL; GRIMM-CABRAL, 1984), reformulado por Scliar-Cabral e Grimm-Cabral (1984). A fim de organizarmos os dados, elaboramos um quadro com categorias relativas ao esquema narrativo e a convenções de escrita. Isso permitiu visualizarmos as dificuldades dos alunos na escrita de narrativas. O diagnóstico apontou problemas relacionados aos elementos de coesão no texto, à ortografia e, principalmente, à estrutura do esquema narrativo. Com referência a esse último aspecto, foram constatadas questões relacionadas à fórmula inicial e final, referência espacial (cenário), descrição das personagens, relação de causa e consequência, elementos de retomada (anafóricos) e à quantidade de episódios da narrativa. Para ilustrar, trazemos um dos quadros que serviu de diagnóstico:

Quadro I - Diagnóstico das Produções Textuais dos Alunos

\begin{tabular}{|c|c|c|c|c|c|c|c|}
\hline \multirow[b]{2}{*}{ 总 } & \multirow[b]{2}{*}{$\frac{\frac{0}{\tilde{W}}}{\frac{\pi}{2}}$} & \multirow[b]{2}{*}{ 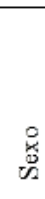 } & \multicolumn{5}{|c|}{ CATEGORIAS } \\
\hline & & & Título & $\begin{array}{c}\text { Fórmula } \\
\text { inicial }\end{array}$ & $\begin{array}{c}\text { Referência } \\
\text { espacial - } \\
\text { cenário }\end{array}$ & Personagens & $\begin{array}{l}\text { Relação de } \\
\text { causa e } \\
\text { consequência }\end{array}$ \\
\hline & & & \multicolumn{5}{|c|}{ CATEGORIAS } \\
\hline & & & $\begin{array}{c}\text { Anafóricos } \\
\text { (personagens) }\end{array}$ & $\begin{array}{l}\text { Elementos } \\
\text { de coesão - } \\
\text { conectores }\end{array}$ & $\begin{array}{c}\mathrm{N}^{\circ} \mathrm{de} \\
\text { episódios }\end{array}$ & $\begin{array}{c}\text { Fórmula } \\
\text { final }\end{array}$ & Observações \\
\hline & & & & & & & \\
\hline
\end{tabular}

Fonte: quadro elaborado pelos bolsistas do Subprojeto Letras-Português do PIBID.

Com o propósito de reverter essa situação e ajudar os alunos a melhorar sua escrita, foram feitas intervenções nas aulas de Língua 
Portuguesa por meio de um projeto de letramento interdisciplinar relatado mais adiante.

\section{A escola campo de atuação}

Antes de iniciarmos as ações do Subprojeto, fizemos uma visita à escola para conhecimento do campo em que iríamos atuar. Buscamos informações relacionadas à estrutura e às rotinas escolares, bem como aos materiais didáticos e paradidáticos disponíveis para auxiliar nos trabalhos com os alunos.

Pudemos constatar que a escola tem à disposição diversas ferramentas de tecnologia, além de laboratórios de informática, biblioteca com um acervo amplo e atualizado e um grande auditório que nos ajudou na elaboração de todos os trabalhos com os alunos. $\mathrm{O}$ fato de termos a nossa disposição tais tecnologias contribuiu para a concretização do projeto, pois pudemos levar os alunos aos laboratórios para fazer pesquisas, para produzir os gêneros discursivos relacionados aos curtas, além de fazer as edições dos vídeos. As salas com projetores multimídia também tiveram grande importância, pois facilitaram o trabalho com os textos multissemióticos e hipermidiáticos (ROJO; MOURA, 2012) necessários para o desenvolvimento do projeto.

No período vespertino, o Subprojeto de Ciências do PIBID, também da FURB, desenvolvia ações no Clube de Ciências da escola. Esse Subprojeto foi de grande importância, pois deu todo o apoio no que se referiu à temática da sustentabilidade. Alguns alunos participavam do Clube de Ciências, no contraturno, e auxiliavam os demais colegas dos grupos na elaboração dos roteiros e a inserirem, de forma efetiva, o tema sustentabilidade socioambiental na produção dos curtas.

O ambiente escolar foi um lugar de aprendizagem e também um espaço utilizado como set de filmagens por algumas equipes nas Olh@res, Guarulhos, v. 2, n. 2, p. 352-374. Dezembro, 2014. 
gravações de cenas dos curtas. Lá os alunos encontraram um palco seguro para construírem suas histórias com muita criatividade, que nós, bolsistas, vimos surgir.

\section{O trabalho com projetos de letramento e a interdisciplinaridade}

A proposta para trabalhar com um projeto de letramento na escola campo de atuação trouxe inicialmente certa insegurança ao grupo de bolsistas $^{2}$, devido ao fato de ser nossa primeira experiência com essa prática pedagógica. Ao mesmo tempo, impôs-nos um desafio: romper com a prática pedagógica tradicional centrada nos conteúdos curriculares segmentados em disciplinas (OLIVEIRA; TINOCO; SANTOS, 2011). Ao trabalhar com projetos, busca-se uma opção para dar outro sentido aos processos habituais de ensinar e aprender, possibilitando aos alunos a construção de conhecimentos e o envolvimento em ações concretas, palpáveis, inseridas no cotidiano deles e em diferentes esferas sociais.

Kleiman (2000, p. 238) sustenta que os projetos de letramento são eficazes no ensino de diferentes textos, propiciando aos educandos um aprendizado que vai além da abstração das palavras.

Por projeto de letramento entendemos um conjunto de atividades que se origina de um interesse real na vida dos alunos, e cuja realização envolve o uso da escrita, isto é, a leitura de textos que, de fato, circulam na sociedade e a produção de textos que serão lidos, em um trabalho coletivo de alunos e professor, cada um segundo sua capacidade. O projeto de letramento é uma prática social em que a escrita é utilizada para atingir algum outro fím, que vai além da mera aprendizagem da escrita (a aprendizagem dos aspectos formais apenas), transformando objetivos circulares como "escrever para aprender a escrever" e "ler para aprender a ler" em ler e escrever para compreender e aprender aquilo que for relevante para o desenvolvimento e realização do projeto. (KLEIMAN, 2000, p. 238, grifos da autora).

O trabalho com projetos de letramento também pressupõe o engajamento de outros profissionais, professores e disciplinas de áreas

${ }^{2\urcorner}$ O grupo de bolsistas, no total de cinco, que atuou na escola, era formado, na sua maioria, por acadêmicos em fase inicial do Curso de Letras.

Olh@res, Guarulhos, v. 2, n. 2, p. 352-374. Dezembro, 2014. 
distintas, que possam contribuir de forma direta ou indireta nesse processo, promovendo dessa forma um trabalho interdisciplinar

[...] o desenvolvimento de projetos na escola pode ser uma alternativa de ressignificação do fazer docente e discente desde que seja pressuposto um trabalho coletivo de planejamento e execução de atividades que têm objetivos e metas compartilhadas por profissionais com diferentes formações [...] (OLIVEIRA; TINOCO; SANTOS, 2011, p. 20).

O nosso projeto envolveu diretamente os Subprojetos LetraPortuguês e Ciências do PIBID, como mencionado anteriormente. Como bolsistas do Subprojeto Letras-Português, buscamos desenvolver ações pedagógicas que promovessem o estudo e a produção escrita dos gêneros discursivos envolvidos nas etapas de elaboração de um filme de curta-metragem. Assim, a prática pedagógica abrangeu o trabalho com os seguintes gêneros e suportes: o storyline, a sinopse/argumento, o conto (gênero escolhido para ser adaptado), o roteiro, a capa do DVD e o cartaz do filme. Esse trabalho, realizado essencialmente nas aulas de Língua Portuguesa, ficou sob a responsabilidade do Subprojeto de Letras. No entanto, o Subprojeto de Ciências $^{3}$ deu o suporte necessário para o desenvolvimento da temática da sustentabilidade, num trabalho efetivamente coletivo entre os acadêmicos e supervisores envolvidos.

\section{O projeto "Curta-metragem na sala de aula": relato de uma experiência}

Com o projeto "Curta-metragem na sala de aula" tivemos desde o início o propósito de trabalhar interdisciplinarmente, unindo práticas de letramentos com conhecimentos sobre o tema escolhido,

\footnotetext{
$\left.{ }^{3}\right\urcorner$ O Subprojeto de Ciências do PIBID coordena o Clube de Ciências da escola, que vem desenvolvendo ações sociais como a Conferência Infanto Juvenil pelo Meio Ambiente, realizada em 2013, em que foi discutida a temática da sustentabilidade escolar.

Olh@res, Guarulhos, v. 2, n. 2, p. 352-374. Dezembro, 2014.
} 
juntamente com o Subprojeto de Ciências. Por meio de uma formação na Universidade, que teve como tema a produção de vídeos com alunos do Ensino Médio, tivemos a oportunidade de conhecer uma metodologia de ensino que alia vários gêneros discursivos e o uso de tecnologias, para a produção de curta-metragem. Esse tipo de prática, em geral, atrai a atenção dos alunos, acostumados a lidar com as tecnologias de informação, mas que nem sempre encontram na escola um espaço que lhes proporcione a inserção em práticas de letramento digital.

Iniciamos o projeto escolhendo, em conjunto com a supervisora, três turmas da $8^{\mathrm{a}}$ série e, a partir disso, trabalhamos algumas dificuldades da escrita dos alunos, diagnosticadas em etapas anteriores do Subprojeto. Discutimos com as turmas as principais recorrências dos erros ortográficos que haviam cometido, a falta de coesão e de elementos de retomada (anafóricos), as dificuldades na elaboração das suas narrativas, principalmente, no tocante à estrutura, envolvendo a introdução, complicação, clímax e desfecho. Trabalhamos de forma coletiva a causa da ocorrência desses erros e, dessa forma, observamos que os alunos aprenderam a partir de suas próprias dificuldades. No final desse trabalho, mostraram um grande avanço em relação à produção escrita.

Após essa etapa, iniciamos o projeto "Curta-metragem na sala de aula" propriamente dito, detalhando e discutindo o trabalho com os alunos, mostrando a sequência de ações que seria percorrida ao longo do processo. Como encaminhamento metodológico de trabalho, organizamos algumas sequências didáticas (DOLZ; NOVERRAZ; SCHNEUWLY, 2004), de maneira sistemática, que iriam servir de base para o andamento do projeto. $\mathrm{O}$ esquema com os respectivos módulos, que se apresenta, também mostra em qual etapa cada Subprojeto do PIBID atuou:

Olh@res, Guarulhos, v. 2, n. 2, p. 352-374. Dezembro, 2014. 


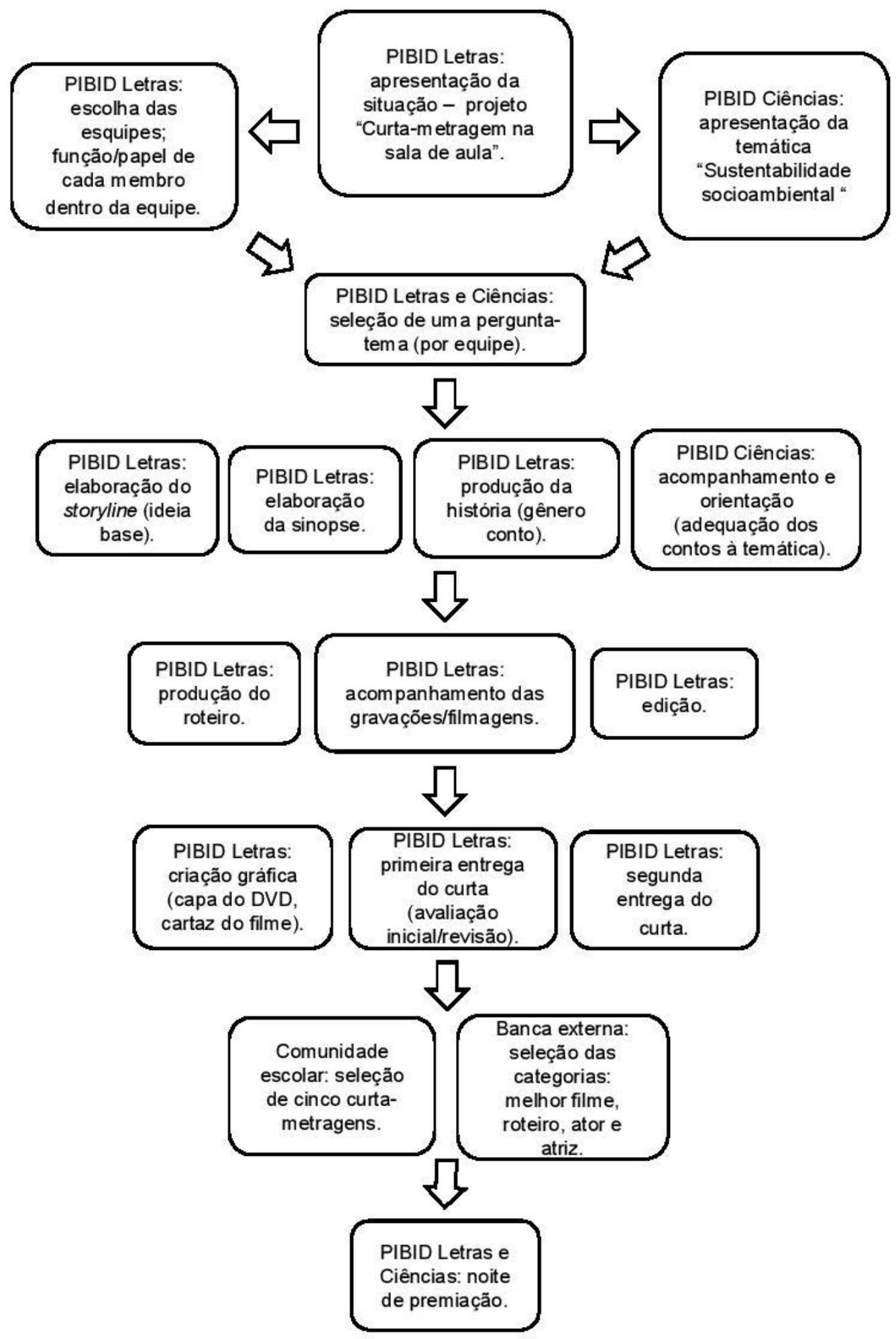

Fonte: esquema elaborado pelos bolsistas do Subprojeto Letras-Português do PIBID.

Olh@res, Guarulhos, v. 2, n. 2, p. 352-374. Dezembro, 2014. 
Cada módulo descrito na esquematização do projeto foi pensado tendo por base o calendário escolar e o número de aulas das professoras de Língua Portuguesa e de Ciências.

No primeiro encontro, apresentamos a situação de comunicação com a qual iríamos trabalhar e detalhamos o projeto do curta. Nesse dia, também foi feita a separação das turmas em equipes e a divisão das funções de cada integrante, ou seja, cada aluno teria um papel específico dentro do grupo como: diretor, produtor, roteirista, editor, operador de câmera e ator. Discutimos em conjunto com os alunos as atribuições de cada uma dessas funções, assim, cada equipe definiu o papel de cada membro dentro do seu grupo. Nesse momento, também procuramos motivar os alunos mostrando que independentemente de qual função dentro da equipe fossem exercer, eles deveriam estar cientes de que o produto do projeto, o filme, seria fruto de um esforço coletivo.

Os bolsistas do PIBID de Ciências deram a sua contrapartida inicial, articulando com as turmas discussões relacionadas à consciência ecológica, promovendo reflexões sobre a sustentabilidade no âmbito social, ambiental e econômico. Como estratégia de ensino, naquele momento, eles fizeram um levantamento com as turmas sobre os conhecimentos prévios dos alunos acerca dos conceitos de sustentabilidade tanto no âmbito local (micro), quanto no global (macro). A partir daí os conceitos foram sendo construídos com os alunos.

Com a temática da sustentabilidade socioambiental como mote, cada equipe teria como meta criar um filme de curta-metragem, com duração de 4 a 10 minutos, cujo roteiro respondesse a, pelo menos, uma das seguintes questões:

- O que podemos fazer para transformar nossa escola, cada vez mais, em um ambiente saudável, inclusivo, seguro, sustentável e educador? 
- O que precisamos saber para enfrentar as mudanças socioambientais e contribuir para a preservação da vida com qualidade para as presentes e futuras gerações?

- Quais os valores e as atitudes necessários para a construção da sustentabilidade socioambiental?

- O que a sociedade blumenauense aprendeu com a catástrofe de 2008? Ou: Desde a catástrofe de 2008, como a cidade de Blumenau tem lidado com as questões socioambientais?

A propósito da temática, sua escolha se deu, conforme mencionado anteriormente, pela necessidade premente de se trabalhar aspectos relacionados à consciência ecológica e à ecoformação (TORRE; ZWIEREWICZ, 2009), de acordo com a proposta dos temas transversais (BRASIL, 1998). Também foi incluída uma questão específica sobre a realidade local, a fim de que os alunos refletissem sobre os problemas locais em conexão com os globais.

Os grupos selecionaram uma das perguntas, recebendo a nossa orientação e, também, dos pibidianos de Ciências. Após a escolha da pergunta tema, teve início a produção escrita, com a elaboração da ideia base da história (storyline) que, segundo Bayão (2002, p. 26), “[...] é a história contada em, no máximo, um parágrafo". Nessa etapa do projeto, iniciamos com alguns conceitos acerca da ideia básica, podendo ser ficcional ou baseada em fatos reais. Discutimos com as turmas que um filme nasce a partir do surgimento de muitas ideias, mas somente uma será o eixo que dará o percurso narrativo. Resumível a uma frase ou parágrafo, deve apresentar um ou mais protagonistas, envolvendo um conflito, cujo final, desfecho, já pode ficar definido. Nesse momento, cada equipe também optou em relação à qual gênero cinematográfico sua história seria tecida: drama, suspense, policial, comédia, romance entre outros.

Levamos para a sala de aula alguns exemplos de storylines com o objetivo de promover o contato com o gênero discursivo e Olh@res, Guarulhos, v. 2, n. 2, p. 352-374. Dezembro, 2014. 
motivar os alunos na criação das suas ideias iniciais, como a que segue:

"Casal se conhece recolhendo lixo reciclável e, após um casamento sustentável, descobrem que eram irmãos."

Alguns grupos se mostraram sensíveis às causas ambientais e demonstraram criatividade. A partir daí, percebemos que grandes histórias estariam por vir, como pode ser verificado nos storylines abaixo:

“Jovem tenta impedir que um empresário construa um hotel de luxo em uma área preservada. Assim, entra na justiça, comovendo e mobilizando toda a cidade a ajudá-la." (Equipe A)

"Menina desaparece durante as enchentes de 2008 e após alguns anos ela descobre que seu colega de sala de aula era seu irmão." (Equipe B)

"Um grupo de jovens busca aventura em meio à natureza. Após tomar banho no rio, o jovem Jeremy Gilbert contrai uma doença que o leva à morte, pois a água do rio estava contaminada." (Equipe $\mathrm{C}$ )

Com a ideia base formulada, passamos para a produção escrita de outro gênero, a sinopse. É mais uma etapa importante, pois, agora, os alunos teriam que elaborar um resumo mais detalhado, já apresentando de forma mais complexa o argumento da história. É a alma do filme retratada em poucos parágrafos, apresentando os personagens, o conflito e o desfecho da narrativa. Para ilustrar essa etapa, mencionamos uma das sinopses em que pudemos observar como os alunos foram articulando as características do gênero à temática da sustentabilidade e à história que estava por vir:

"Joana é uma jovem apaixonada pela natureza. Todos os dias ela medita em uma área preservada, que é o seu lugar preferido.

Olh@res, Guarulhos, v. 2, n. 2, p. 352-374. Dezembro, 2014. 
Maristela Pereira Fritzen, Aline Fernanda Guse, Eriberto Manoel Moreira, Andressa Regiane Gesser \& Larissa Patricia Theiss

Certo dia, ela ouve o barulho de pessoas andando e acha estranho. Ao verificar o que está acontecendo, descobre que será construído um hotel de luxo naquele local. Inconformada, vai tirar satisfações com o dono da rede de hotéis Environment. O empresário está disposto a passar por cima de qualquer coisa para construir esse hotel.

A jovem precisa fazer algo para impedir que isso ocorra e entra na justiça para interromper a obra. Ela enfrentará muitos problemas, mas sua maravilhosa ação começa a repercutir na mídia, comovendo e mobilizando toda a cidade a ajudá-la. Sua determinação e coragem impedirão a construção do hotel. "Hotéis Environment" nos conduzirá a uma reflexão sobre a relação existente entre o homem e a natureza.". (Equipe A)

A equipe "A" optou por responder à pergunta tema "O que precisamos saber para enfrentar as mudanças socioambientais e contribuir para a preservação da vida com qualidade para as presentes e futuras gerações?". Percebe-se no storyline e na sinopse da mesma equipe coerência na articulação das ideias com a pergunta tema selecionada. Incorporar o tema proposto ao projeto do filme que teriam que desenvolver nem sempre se mostrou uma tarefa fácil para as equipes. Nesses dois módulos que se sucederam, algumas equipes apresentaram dificuldades em relação a essa adequação. Em algumas situações, os grupos recuaram reelaborando novos storylines $\mathrm{e}$ sinopses. Isso fez com que houvesse replanejamento do cronograma a fim de que pudéssemos ajudar os alunos a ajustar à temática à ideia das equipes.

Vencida essa etapa, partimos para a produção escrita da história, do conto que serviria de base à narrativa do curta, tendo em vista as características desse gênero discursivo, como poucas personagens, que existem em função de um único núcleo. Uma das nossas dificuldades durante a realização desse projeto foi não ter Olh@res, Guarulhos, v. 2, n. 2, p. 352-374. Dezembro, 2014. 
localizado nenhum conto que contemplasse a temática da sustentabilidade e que tivesse sido adaptado a filme de curtametragem. Dessa forma, levamos para a sala de aula outros materiais impressos e vídeos alternativos com o objetivo de trabalhar as principais características do gênero. Dentre os procedimentos metodológicos utilizados nesse módulo, os alunos assistiram a filmes de curta-metragem adaptados de contos como "O Falcão", de Luís Fernando Veríssimo, e o curta premiado "Laços", roteiro de Adriana Falcão. Outro conto trabalhado com os alunos foi "O Plebiscito", de Arthur Azevedo com o qual detalhamos alguns operadores de leitura das narrativas (ZOLIN; BONNICI, 2003) como: nó, clímax e desfecho. Outros elementos da narrativa como narrador, personagens, tempo, espaço e enredo também foram abordados nessa fase.

No decorrer desse módulo, auxiliamos os alunos a aprimorarem as narrativas que iam construindo e reconstruindo/reescrevendo com criatividade. Fomos observando que cada vez mais eles uniam os conhecimentos que haviam construído durante as aulas e oficinas com a imaginação em criar histórias.

Após o processo de elaboração do storyline, sinopse e conto, partimos para o próximo gênero: o roteiro. Nessa etapa, os alunos adaptaram seus contos para o gênero cinematográfico roteiro. Segundo Field (2001, p. 2), "o roteiro é uma história contada em imagens, diálogos e descrições, localizada no contexto da estrutura dramática”. Já para Bayão (2002, p. 13), “o roteiro cinematográfico é o primeiro passo na produção de um filme. É a peça chave que alavanca todos na equipe para um objetivo comum - o de contar uma história”.

Talvez esse tenha sido o maior desafio que as equipes tiveram pela frente, e que também se estendeu a nós, bolsistas, já que nunca havíamos tido contato com o gênero roteiro até entrarmos no Subprojeto. Ao longo dos meses que antecederam o projeto do curta tivemos algumas formações, incluindo o trabalho com roteiro e 
produção de curta-metragem, além de assistirmos a uma palestra, em Blumenau, com a roteirista Adriana Falcão da TV Globo.

Levamos para a sala de aula alguns livros e outros impressos como o "Manual do Roteiro", de Syd Field, e "Escrevendo Curtas", de Luiz Gustavo Bayão para as equipes explorarem o gênero. A maioria nunca havia trabalhado com o gênero discursivo roteiro. A partir desses materiais pudemos perceber a importância dele no cotidiano dos profissionais do cinema e da televisão, como uma ferramenta que articula a passagem da teoria para a prática.

Devido à relevância desse gênero no projeto que estávamos desenvolvendo e o curto espaço de tempo para trabalhá-lo em sala de aula, ministramos uma oficina/minicurso de quatro horas/aula no contraturno, com ênfase nas suas principais características. Também orientamos as equipes no uso de programas de computador específicos para elaborar roteiros como o $\mathrm{CELTX}^{4}$, o que acabou facilitando o trabalho de alguns grupos. Os roteiros entraram na formatação necessária para que as gravações fossem feitas com o cuidado que exigem. Vale salientar, para a nossa surpresa, que a maioria dos roteiros atingiu de 10 a 12 páginas em média, com trabalhos que articularam de forma satisfatória a temática à história.

Com os roteiros finalizados, passamos para a fase seguinte, as gravações. A maioria dos nossos jovens cineastas utilizou como recurso de gravação os seus aparelhos de telefone móvel. Os alunos não tiveram dificuldades nessa fase, já que eles têm domínio sobre o uso dessas tecnologias. As equipes se organizaram para realizar as gravações, nos horários do contraturno e nos finais de semana. Cada dia em que acompanhávamos as gravações percebíamos que os alunos estavam engajados em construir um bom trabalho para mostrar a todos.

\footnotetext{
${ }^{4}$ Freeware-um software que pode ser adquirido e usado sem custo na World Wide Web. Olh@res, Guarulhos, v. 2, n. 2, p. 352-374. Dezembro, 2014.
} 
As locações para as gravações aconteceram em espaços diversos conforme os cenários que cada história exigia. Um dos locais de gravações foi em uma área verde onde, de acordo com a história, seria construído um hotel de luxo; outro local foi o estacionamento da Prefeitura Municipal, já que, nesse caso, a história tinha como uma das personagens, o prefeito, trazendo à tona a catástrofe do ano de 2008 que assolou a nossa região; outras locações escolhidas foram o Corpo de Bombeiros da cidade, as casas dos alunos e, principalmente, a própria escola que também serviu de cenário durante as gravações. Algumas equipes contaram com a participação de outras pessoas da comunidade para interpretar papéis como crianças e pessoas idosas; um integrante do Corpo de Bombeiros também atuou como uma das personagens. A escola providenciou um ofício explicando e solicitando autorização para gravação em locais públicos externos à escola, como a Prefeitura Municipal, um hospital e o Corpo de Bombeiros.

Finalizadas as gravações, as equipes se empenharam na edição dos curtas, utilizando programas para edição de áudio e vídeo como o Windows Live Movie Maker, Sony Vegas, Adobe Premiere, Final Cut, entre outros. Finalmente os grupos trabalharam na elaboração gráfica da capa do DVD e do cartaz do filme, tendo o nosso acompanhamento e as nossas orientações.

Após a primeira entrega dos curtas, percebemos que os vídeos necessitariam de ajustes devido, por exemplo, a problemas no áudio, principalmente nas gravações realizadas em áreas externas. Assim, orientamos as equipes para incluir legendas.

Todo o processo levou cerca de três meses, com a produção final de dez filmes de curta-metragem, envolvendo três turmas de $8^{\text {a }}$ série e alguns alunos do Clube de Ciências da escola. Os dez curtas produzidos foram:

- Aprendendo a viver ( $8^{\mathrm{a}}$ série $\left.\mathrm{A}\right)$

- Círculos em fogo ( $8^{\mathrm{a}}$ série A)

Olh@res, Guarulhos, v. 2, n. 2, p. 352-374. Dezembro, 2014. 
- Complexo 10 - A Última chance (Clube de Ciências)

- Epidemia ( $8^{\mathrm{a}}$ série B)

- Hotéis environment $\left(8^{\mathrm{a}}\right.$ série $\left.\mathrm{C}\right)$

- Meu novo mundo ( $8^{\mathrm{a}}$ série $\left.\mathrm{C}\right)$

- O acampamento do medo ( $8^{\mathrm{a}}$ série $\left.\mathrm{B}\right)$

- O reencontro $\left(8^{\mathrm{a}}\right.$ série $\left.\mathrm{B}\right)$

- Rosane ( $8^{\mathrm{a}}$ série $\left.\mathrm{C}\right)$

- Unidos pelo destino ( $8^{\mathrm{a}}$ série A)

Em conjunto com o Subprojeto de Ciências e com a gestão da escola, decidimos que a comunidade escolar (alunos e professores) selecionaria cinco desses curtas para concorrerem aos prêmios de melhor curta, melhor roteiro, melhor ator e melhor atriz. A escolha final dos vencedores se deu por meio de uma seleção feita por uma equipe externa composta por professores da Universidade e do PIBID, alguns acadêmicos dos cursos de Ciências e Publicidade e Propaganda, além de representantes da Secretaria Municipal de Educação, todos convidados para participar do processo.

O PIBID de Ciências disponibilizou os cinco curtas escolhidos pela comunidade escolar no Youtube, por meio de um grupo fechado. Assim, os avaliadores puderam acessar os filmes para apreciá-los, com base em critérios de avaliação dispostos em uma ficha elaborada por nós.

No fechamento dos trabalhos, realizamos uma noite cultural para premiação das categorias vencedoras. Esse evento contou com a participação dos alunos, pais, professores e autoridades que representaram o PIBID da Universidade e a Secretaria de Educação do município. Dessa forma, concluímos o projeto na escola com a certeza de que o trabalho com "projetos", quando há o engajamento de todos por um fim comum, pode tornar possível aprendizagens significativas para todos os envolvidos.

\section{Considerações finais}

Olh@res, Guarulhos, v. 2, n. 2, p. 352-374. Dezembro, 2014. 
Ao finalizarmos os trabalhos com os alunos do Ensino Fundamental, verificamos que houve um avanço nas produções escritas desses estudantes. Ao compararmos seus primeiros textos, quando iniciamos o trabalho na escola, em que algumas produções não passavam de poucas linhas, surpreendemo-nos com a maioria dos roteiros apresentados pelas equipes durante a finalização da parte escrita do curta com cerca de 10 a 12 páginas de roteiro em média.

Os resultados alcançados com o projeto foram além das nossas expectativas, principalmente se considerarmos o curto espaço de tempo que tivemos para pô-lo em prática (de agosto a novembro/2013), e também por ter sido a primeira vez que um projeto desse tipo foi realizado na escola campo de atuação. Talvez a palavrachave nesse processo tenha sido "desafio", tanto para nós, bolsistas do PIBID, quanto para os alunos das oitavas séries. Constatamos que o trabalho com projetos requer muito mais capacidades, além do domínio dos conteúdos específicos das disciplinas curriculares, pois, embora houvesse um planejamento inicial, foi preciso rever o plano em certas etapas, adequando-o a novos conteúdos e prazos por meio de decisões coletivas.

Foi uma experiência de muita aprendizagem, pois pudemos trabalhar interdisciplinarmente a temática da sustentabilidade socioambiental, conforme previsto nos objetivos do projeto. Diante dessa perspectiva de trabalho, que não parte de conteúdos pré-fixados em cada disciplina para cada ano, mas de práticas sociais, pudemos refletir sobre os tempos e espaços na escola a fim de promover contextos efetivos de aprendizagem. O tema trabalhado também nos permitiu refletir sobre que sociedade queremos para o futuro e que tipo de professores queremos e podemos ser adiante. Esse trabalho atingiu não somente os professores e os alunos, como também a coordenação, a direção da escola e os pais, que se mostraram engajados desde as primeiras produções escritas até as gravações dos vídeos.

Olh@res, Guarulhos, v. 2, n. 2, p. 352-374. Dezembro, 2014. 
Além do acompanhamento que fizemos com os alunos em cada etapa do projeto de letramento, tivemos a chance de participar ativamente do cotidiano da escola e perceber que a escola, além de um ambiente de aprendizagem e construção de saberes, é também um espaço para o desenvolvimento de senso crítico e de sociabilidade. É nela que aprendemos a viver em sociedade.

Para nós, o projeto ensinou muito, pois possibilitou a efetiva interlocução entre a Universidade e a educação básica, por meio de ações conjuntas entre docentes/ pesquisadores, professores supervisores e acadêmicos. Assim, aprendemos a unir a teoria à prática e adquirimos experiência interdisciplinar na fase de iniciação à docência. 


\section{Referências bibliográficas:}

ABREU, M. N. Narrativa ficcional: comparação entre textos de 1982 e de $2011 \mathrm{em}$ crianças dos 4 a 6 anos. 2012. 209 f. Dissertação (Mestrado em Linguística) Programa de Pós-Graduação em Linguística, Universidade Federal de Santa Catarina, Florianópolis, 2012.

BAKHTIN, M. Estética da criação verbal. São Paulo: Martins Fontes, 1997.

BAYÃO, L. G. Escrevendo curtas: uma introdução à linguagem cinematográfica do curta-metragem. Rio de Janeiro: L. G. Bayão, 2002.

BRASIL. Secretaria de Educação Fundamental. Parâmetros Curriculares Nacionais: meio ambiente. Terceiro e quarto ciclos do ensino fundamental. Brasília: MEC/SEF, 1998.

CABRAL, L. S. Introdução à psicolinguística. São Paulo: Ática, 1991.

DOLZ, J.; NOVERRAZ, M.; SCHNEUWLY, B. Seqüências didáticas para o oral e a escrita: apresentação de um procedimento. In: DOLZ, J.; SCHNEUWLY, B. Gêneros orais e escritos na escola. Campinas: Mercado de Letras, 2004. p. 95-128.

FIELD, S. Manual do roteiro: os fundamentos do texto cinematográfico. Rio de Janeiro: Objetiva, 2001.

FRITZEN, M. P. Subprojeto PIBID Letras-Português. Blumenau: FURB, 2011. p. 3.

GUIMARÃES, A. M. M. Construindo propostas de didatização de gênero: desafios e possibilidades. Linguagem em (Dis)curso, v. 6, n. 3, p. 1-12, set./dez. 2006.

KLEIMAN, A. B. Os significados do letramento. Campinas: Mercado de Letras, 1995.

- O processo de aculturação pela escrita: ensino da forma ou aprendizagem da função? In: KLEIMAN, A. B.; SIGNORINI, Inês. O ensino e a formação do professor: alfabetização de jovens e adultos. Porto Alegre: ARTMED, 2000. p. 223243.

- Os estudos do letramento e a formação do professor de língua materna. Linguagem em (Dis)curso - LemD, v. 8, n. 3, p. 487-517, set./dez. 2008.

CENICEROS, R. C.; TINOCO, G. A. Projetos de letramento no ensino médio. In: BUNZEN, C.; MENDONÇA, M. (Orgs.). Múltiplas linguagens para o ensino médio. São Paulo: Parábola Editorial, 2013. p.69-83.

OLIVEIRA, M. S.; TINOCO, G. M. A. de M.; SANTOS, I. B. A. Projetos de letramento e formação de professores de língua materna. Natal: EDUFRN, 2011.

Olh@res, Guarulhos, v. 2, n. 2, p. 352-374. Dezembro, 2014. 
ROJO, R.; MOURA, E. (orgs.) Multiletramentos na escola. São Paulo: Parábola Editorial, 2012.

SCLIAR-CABRAL, L.; GRIMM-CABRAL, L. Caracterização das qualidades narrativas em pré escolares. In: Ilha do Desterro: a bilingual journal of language and literature. Florianópolis, v.11, p. 56-74, 1984.

SILVA, M. E. L.; SPINILLO, A. G. Uma análise comparativa da escrita de histórias pelos alunos de escolas públicas e particulares. Revista Brasileira de Estudos Pedagógicos, Brasília, v. 79, n. 193, p. 5-16, set./dez. 1998.

- A influência de diferentes situações de produção na escrita de histórias. Psicologia: Reflexão e Crítica, v.13, n. 3, p. 337-350, 2000.

TORRE, S.; ZWIEREWICZ, M. Uma escola para o século XXI: escolas criativas e resiliência na educação. Florianópolis: Insular, 2009.

ZOLIN, L. O.; BONNICI, T. Teoria literária: abordagens históricas e tendências contemporâneas. Maringá: Eduem, 2003. 